\title{
Undergraduate optics program for the 21st Century
}

\section{James Palmer}

James M. Palmer, "Undergraduate optics program for the 21st Century," Proc. SPIE 4588, Seventh International Conference on Education and Training in Optics and Photonics, (28 May 2002); doi: 10.1117/12.468749

SPIE Event: Education and Training in Optics and Photonics 2001, 2001, Singapore, Singapore 


\title{
An undergraduate optics program for the $21^{\text {st }}$ century
}

\author{
James M. Palmer, Optical Sciences Center, University of Arizona \\ Tucson, Arizona
}

\begin{abstract}
We have been offering a successful BS degree in optical engineering for the past ten years. We have produced more than 100 graduates, highly trained in basic optics and electronics. Our Industrial Affiliates, while very pleased with our graduates, requested that we produce some with greater mechanical engineering skills and knowledge. Our response was the creation of a new degree program, retaining the virtues of the previous one, but allowing a high degree of flexibility through the inclusion of minors within the program. The new program allows sufficient room for a variety of minors. Engineering minors identified include aerospace, computer, electrical, materials and mechanical. Science minors include astronomy, computer science, math and physics. Non-science minors accommodated include business, pre-health and pre-law.
\end{abstract}

The new BSO program features:

(1) Better structure and flow, more tightly coupling related classes

(2) New laboratory classes for juniors, linked to lecture classes

(3) Expanded optical design, fabrication and testing classes

(4) New class in electronics for optics

(5) New classes in fiber optics and optical communications

(6) New capstone/senior project class for ABET compliance

This new BSO program will produce better entry-level optical scientists and engineers, and better candidates for graduate school. Our interactions with the external community will provide inputs concerning industrial needs, leading towards improved student counseling and program development. We will better serve national needs for skilled personnel in optics, and contribute even more to the optics workforce pipeline.

\section{OPTICAL SCIENCES CENTER}

The Optical Sciences Center at the University of Arizona conducts one of the foremost teaching and research programs in optics. It was founded in 1964 by the visionary Aden Meinel, who also founded Kitt Peak National Observatory. He attracted a first-rate faculty, drawn from academia, government and industry. The initial MS degree was granted in 1968 , and the initial PhD degree was awarded in 1969. The $~ 75,000$ sq. ft. building housing OSC was dedicated in January 1970, and an additional 45,000 sq ft was added in 1990. A typical snapshot shows 80 undergraduate students and 180 graduate students. We now have produced nearly 1000 graduates; approximately $100 \mathrm{BS}, 300 \mathrm{MS}$ and $600 \mathrm{PhD}$.

\section{MISSION STATEMENT}

The mission of the Optical Sciences Center is to provide the state of Arizona, the United States, and the world with an internationally prominent program in education, research, and outreach in all aspects of the science and application of light. 


\section{UNDERGRADUATE PROGRAM HISTORICAL BACKGROUND}

In the middle 1980's there were numerous unfilled jobs suited for the knowledge and skills commensurate with the Bachelor's level of education. BSEE or BS Physics graduates staffed most of the available positions, and their abilities to do optics were limited. Our graduate program (MS \& PhD) was by this time 20 years old, and had already earned the reputation for producing outstanding graduates. The original impetus for the establishment of a BS program came in the form of requests from our Industrial Affiliates. They needed more suitable entry-level employees than they were able to obtain from the pool of recent graduates, and they suggested that we initiate a BS degree program.

\section{INDUSTRIAL AFFILIATES}

The Industrial Affiliates are a select group of some 40 companies in the industrial sector that provide institutional support to the Optical Sciences Center. Funding from the Industrial Affiliates provides for support for:

- undergraduate program (financial aid, academic support and advising capabilities, and improved classroom and laboratory facilities)

- graduate program (recruiting, first-year funding, and teaching laboratory equipment)

- faculty support (start-up funds for new faculty in key disciplines, funding for endowed distinguished professor chairs)

- technology transfer activities (improve communications with industry in areas of research findings, patent and licensing initiatives, and collaborative research)

We listened! Initial plans were made in 1984, and the final approval from the Arizona Board of Regents was obtained in 1988. We accepted our first students at the sophomore level in the fall semester of 1989. Our first class of seven students graduated in 1992.

The mission of the Undergraduate Program is to educate optical engineers who will be productive immediately upon graduation in areas involving optical design, fabrication and testing, lasers, optical detectors, optical instrumentation, etc.

\section{BSOE PROGRAM DESCRIPTION}

In order to offer an undergraduate degree, the University required us to affiliate with an existing college. We chose the College of Engineering, specifically the ECE department, as most suitable. The degree program established was split approximately $60 \%$ optics and $40 \%$ ECE, so the BSOE degree was in reality a degree in electro-optics or optoelectronics.

The B.S.O.E. was designed as a terminal degree to supply needs of industry, and not to provide input for a graduate program. The degree is conferred by the department of Electrical \& Computer Engineering (ECE). Because of a shortage of available laboratory space and facilities, the enrollment was initially limited to 36 incoming sophomores per year. Administration of the program was handled by a joint committee consisting of ECE and OSC faculty members. The optics component was designed by OSC, the electrical component was designed by ECE, and the faculty was drawn from both departments. The program management and engineering college interface was assigned to ECE.

\section{FEEDBACK FROM AFFILIATES}

This has been a very successful program. By 2001 we have more than 100 graduates that have taken their place in industry or gone on to graduate school. Our Industrial Affiliates agreed. They really like our product, and were continually seeking more. 


\section{BSOE CURRICULUM}

A common first year curriculum is defined for all engineering freshmen. It includes two semesters of calculus, and one semester each of chemistry (with lab), physics (with lab) and engineering materials.

\begin{tabular}{|lc|lc|}
\hline \multicolumn{2}{|c|}{ First Semester } & & \multicolumn{2}{c|}{ Second Semester } & \\
\hline Course & Units & Course & Units \\
\hline OPTI 210 Geometrical Optics & 3 & OPTI 226 Physical Optics & 3 \\
OPTI 210L. Lab & 1 & OPTI 226L Lab & 1 \\
MATH 223 Vector Calculus & 4 & ECE 220 Circuits & 5 \\
PHYS 241 E\&M & 4 & MATH 254 Differential Equations & 3 \\
UA GenEd & 3 & UA GenEd & 3 \\
\hline \multicolumn{1}{|c|}{ TOTAL } & $\mathbf{1 6}$ & \multicolumn{2}{c|}{ TOTAL } \\
\hline
\end{tabular}

\begin{tabular}{|c|c|c|c|}
\hline \multicolumn{4}{|c|}{ JUNIOR YEAR } \\
\hline First Semester & & \multicolumn{2}{|c|}{ Second Semester } \\
\hline Course & Units & Course & Units \\
\hline ECE 274 or 275 "C" or Digital Logic & 3 & ECE 352 Electronic Devices & 3 \\
\hline ECE 320 Circuits & 4 & ECE 381 E\&M & 3 \\
\hline ECE 351A Electronics & 3 & OPTI 342 Fourier Optics & 3 \\
\hline MATH 322 Analysis & 3 & OPTI 370 Lasers, E-O & 3 \\
\hline $\begin{array}{l}\text { OPTI } 350 \text { Radiometry, Sources, } \\
\text { Detectors }\end{array}$ & 3 & PHYS 242 Relativity \& Quantum & 3 \\
\hline TOTAL & 16 & TOTAL & 15 \\
\hline \multicolumn{4}{|c|}{ SENIOR YEAR } \\
\hline First Semester & & Second Semest & \\
\hline Course & Units & Course & Units \\
\hline OPTI 412 Optical Instruments & 3 & OPTI 416 Design, Test & 4 \\
\hline OPTI 470a Senior Lab & 3 & OPTI 470b Senior Lab & 3 \\
\hline UA GenEd & 3 & UA GenEd & 3 \\
\hline Tech Electives & 6 & Tech Electives & 6 \\
\hline TOTAL & 15 & TOTAL & 16 \\
\hline
\end{tabular}

\section{A NEW DIRECTION}

Sometime around 1997, the Industrial Affiliates expressed their desire that we expand our offerings, as they specifically needed optical engineers with more mechanical skills. They had plenty of available EE's. An obvious solution would have been to replace some or all of the ECE courses with appropriate choices from the Aerospace \& Mechanical Engineering (AME) department. This solution would most likely have entailed creation of a new degree, including liaison with yet another department. During discussions, another path soon emerged. Why not offer a degree in optics, and allow the student to select a complementary minor?

We chose to follow the path leading to a new degree program, a BSO degree. This choice allowed a complete restructuring of the curriculum, so we were able to significantly strengthen the optics component by increasing the number of optics courses required. We set aside 18 units to allow the student to select a supporting minor. This choice of a new program required the termination of our affiliation with the ECE department, and OSC would be responsible for all phases of program administration, including the critical task of student advising. Formal approval proceedings were initiated in 1999 and the Arizona Board of Regents approved the new program in 2000. Affiliation with a College was still a requirement, so we joined University College. There is a flexibility inherent in this program allows us to quickly respond to the changing needs of the workplace. Successful completion of this program will produce a competent scientist or engineer ready to enter the job market with a distinct advantage over those with other degrees. The first students in the BSO program began in Fall 2001. 


\section{NEW, IMPROVED B.S. OPTICS CURRICULUM}

We elected to retain the common first year curriculum required for all engineering freshmen, with the exception of the introductory ENGR102. The first year includes two semesters of calculus, and one semester each of chemistry (with lab), physics (with lab) and engineering materials.

\begin{tabular}{|c|c|c|c|}
\hline \multicolumn{4}{|c|}{ SOPHOMORE YEAR } \\
\hline First Semester & & Second Semeste & \\
\hline Course & Units & Course & Units \\
\hline OPTI 201 Geometrical Optics & 3 & OPTI 202 Optical Instrumentation & 3 \\
\hline OPTI 201L Lab & 1 & OPTI 2021. Lab & 1 \\
\hline MATH 223 Vector Calc & 4 & MATH 254 Diff Equations & 3 \\
\hline PHYS 241 E\&M & 4 & PHYS 242 Relativity \& Quantum & 3 \\
\hline Computer Programming & 1 & UA GenEd & 3 \\
\hline Minor \#1 & 3 & Minor \#2 & 3 \\
\hline TOTAL & 16 & TOTAL & 16 \\
\hline
\end{tabular}

\begin{tabular}{|c|c|c|c|}
\hline \multicolumn{4}{|c|}{ JUNIOR YEAR } \\
\hline First Semester & & Second S & \\
\hline Course & Units & Course & Units \\
\hline OPTI 310 Physical Optics I & 3 & OPTI 330 Physical Optics II & 3 \\
\hline OPTI 320 Photonics & 3 & OPTI 340 Optical Design & 3 \\
\hline OPTI 380a Junior Lab & 1 & OPTI 360 Electronics & 3 \\
\hline MATH 322 Analysis for Engineers & 3 & OPTI 380b Junior Lab & 1 \\
\hline UA GenEd & 3 & UA GenEd & 3 \\
\hline Minor \#3 & 3 & Minor \#4 & 3 \\
\hline TOTAL & 16 & TOTAL & 16 \\
\hline
\end{tabular}

\begin{tabular}{|c|c|c|c|}
\hline \multicolumn{4}{|c|}{ SENIOR YEAR } \\
\hline First Semester & & Second Semeste & \\
\hline Course & Units & Course & Units \\
\hline OPTI 400 Radiometry, Sources, Detectors & 3 & OPTI 420 Opto-mechanics & 3 \\
\hline OPTI 410 Optical Fabrication \& Test & 3 & OPTI 440 Optical Communications & 3 \\
\hline OPTI 470a Senior. Lab & 2 & OPTI $470 b$ Senior. L.ab & 2 \\
\hline UA GenEd & 3 & OPTI 498 Capstone & 3 \\
\hline Minor \#5 & 3 & Minor \#6 & 3 \\
\hline TOTAL & 14 & TOTAL & 14 \\
\hline
\end{tabular}

\section{MINORS}

Five complementary minors:

Astronomy (15)

Electrical Engineering (18)

Materials Science \& Engineering (14)

Mechanical Engineering (18)

Physics (9)
Other possible minors:

Aerospace Engineering (18)

Atmospheric Sciences (18)

Computer Engineering (20)

Computer Science (18)

Mathematics (3)

Planetary Sciences (18)

General Business (15)

Pre-Health Professional Thematic Minor (18)

Pre-Law Thematic Minor (18)

NOTE: The number in parenthesis denotes the number of required units to achieve this minor. They may be less than the standard 18 units for a minor because of program overlap.

If a student wishes to concentrate exclusively on optics, one additional mathematics course will fulfill the minor requirements for the Math department and for University College. 


\section{WHAT HAVE WE IMPROVED?}

- Added 15 units in optics and closely related topics

- Sophomore courses reorganized for better integration of theory and practice

- Junior courses reorganized for better integration of Fourier techniques into physical optics

- Added Junior labs to support relevant courses

- Electronics course for optical scientists \& engineers

- Expanded optical design, fabrication \& test sequence to 2 courses, 6 credits

- Added opto-mechanics course

- Added optical communications course

- Added computer programming for optics

- Added senior capstone course (ABET requirement)

\section{WHAT HAVE WE LOST?}

Since we have moved Optical Instrumentation from the senior year to the sophomore year, those instruments requiring an understanding of physical optics must be properly treated at a later time.

COMPARISON: OLD BSOE vs. NEW BSO

\begin{tabular}{|l|c|c|}
\hline PROGRAM & BSOE & BSO \\
\hline \hline University required General Education & 30 & 30 \\
\hline Optics required courses & 30 & 45 \\
\hline ECE Required courses & 18 & \\
\hline Other required courses (Phys, Chem, Math, etc) & 35 & 32 \\
\hline Technical Electives & 12 & \\
\hline Minor courses/technical electives & & 18 \\
\hline TOTAL & 125 & 125 \\
\hline
\end{tabular}

\section{BENEFITS FOR THE STUDENT}

Our primary products are our graduates. We wish to offer to our customers, their future employers, the best possible product. Our students may select among a wide variety of complementary minors to suit the particular interests of themselves and their future employers, and we will advise them on the current and projected needs of industry. If a student desires to concentrate solely on optics, one additional mathematics course will serve the minor requirements for the math department and for University College. The BSO degree is also well suited for preparation for careers correlated with science and engineering, such as business, law and medicine.

\section{BENEFITS FOR FUTURE EMPLOYERS}

Organizations that employ entry-level graduates are our valued customers. We wish to offer to them the best possible product. With the new BSO program, they are no longer limited in the scope of our graduates to those with essentially an ECE minor. They have a choice to seek out optics graduates with complementary skills suited to their specific needs. In addition, projections of future needs of these organizations become our inputs for effective career counseling and curriculum planning, so that we may better serve their long-term requirements.

The new BSO curriculum was presented at the annual Industrial Affiliates meeting in 2001. After a lively discussion, approval of the new program by the Industrial Affiliates was unanimous. 


\section{WHAT'S NEXT?}

After the transfer of the undergraduate program to OSC, the College of Engineering and Mines (COEM) approached us and strongly suggested that everyone would benefit if the college level oversight of the program resided in COEM. The result of that dialog is that the current BSO program as described above is expected to morph into another new, even better program, called BSOSE, for BS in Optical Science and Engineering. This will be a cooperative venture, with certain administrative aspects assigned to COEM and others, specifically the student advising, assigned to OSC. Other similar programs, like engineering math, engineering physics and agricultural engineering, established the precedent for this joint administration. The primary advantage for the program residing in part in the COEM is the ease in which ABET (Accreditation Board for Engineering and Technology) accreditation can be achieved. In fact, we have as of October 2001 successfully completed the initial ABET accreditation process for the former BSOE program, and anticipate award in July 2002. This accreditation will also carry forward to this new BSOSE program. The senior year capstone project is an essential element, and will be conducted with COEM to include group multidisciplinary design activities. The number of units has been increased to 128 to accommodate the introductory ENGR102 course. In addition, the senior Capstone course has been expanded to 6 credits covering the final two semesters.

ABET does not like minors, but prefers well-defined "tracks," with the required courses specified jointly with the other department(s). At this time, tracks with ECE and MSE (Material Science and Engineering) have been defined and another with AME (Aerospace and Mechanical Engineering) is anticipated. The remaining "optics track" will involve the other minors and is not likely to be accredited.

\section{CONCLUSIONS}

We have implemented a new BSO program with a great deal of flexibility. It allows students to get a solid grounding in classical optics, and select from a wide variety of supporting minors. In comparison with the old BSOE program, this new BSO program is better for students, better for employers, and better for OSC. It further emphasizes and utilizes the close working relationship with our Industrial Affiliates. 